\title{
Cytokine Profile in Human Peripheral Blood Mononuclear Leukocytes Exposed to Immunoadjuvant and Adjuvant-Free Vaccines Against Influenza
}

\author{
Mikhail Petrovich Kostinov ${ }^{1,2}$, Nelli Kimovna Akhmatova ${ }^{1}$, \\ Ekaterina Alexandrovna Khromova ${ }^{1 *}$ and Aristitsa Mikhailovna Kostinova ${ }^{3}$ \\ ${ }^{1}$ Department of Immunology, I.I. Mechnikov Research Institute of Vaccines and Sera, Moscow, Russia, ${ }^{2}$ Department of \\ Immunology, Sechenov First Moscow State Medical University, Moscow, Russia, ${ }^{3}$ Department of Immunology, NRC Institute \\ of Immunology FMBA of Russia, Moscow, Russia
}

OPEN ACCESS

Edited by:

Slobodan Paessler:

University of Texas Medical Branch at Galveston, United States

Reviewed by: Alexey V. Seregin,

Takeda Oncology, United States Daniel Roberto Perez,

University of Georgia, United States

*Correspondence:

Ekaterina Alexandrovna Khromova kate.khromova@mail.ru

Specialty section

This article was submitted to Vaccines and Molecular Therapeutics, a section of the journal

Frontiers in Immunology

Received: 02 December 2019 Accepted: 27 May 2020

Published: 30 June 2020

Citation:

Kostinov MP, Akhmatova NK Khromova EA and Kostinova AM (2020) Cytokine Profile in Human

Peripheral Blood Mononuclear

Leukocytes Exposed to

Immunoadjuvant and Adjuvant-Free

Vaccines Against Influenza.

Front. Immunol. 11:1351.

doi: 10.3389/fimmu.2020.01351
Background: In the last decade, adjuvant-containing vaccines, exerting different effects on the immune system, including the production of cytokines, which are one of the most important regulatory systems of the body, are introduced into practice.

Objectives: An effect of the immunoadjuvant polymer-subunit and adjuvant-free vaccines against influenza on the cytokine profile of mononuclear leukocytes in 27 healthy women was studied.

Methods: The study of cytokine profile in human peripheral blood mononuclear leukocytes exposed to vaccines against influenza virus was determined by flow cytometry method (Cytomix FC-500, Beckman Coulter, USA) using the Multiplex-13 test system (Bender MedSystems, Austria).

Results: It was established that all the studied vaccines leaded to somewhat increased levels of Th1/Th2/Th17/Th9/Th22 cytokines in the culture fluid of peripheral blood mononuclear leukocytes (PBML), which indicates the activation of both humoral and cellular immunity. An immunoadjuvant vaccine has been shown to be superior in activating the synthesis of Th1 (IL-12, INF-g, IL-2, IL-6, IL-1 $\beta$, TNF- $\alpha$ ) cytokines, IL-9 and IL-22, while the subunit vaccine was superior in activating the synthesis of IL-4, and split vaccine- of IL-5.

Conclusions: Immunoadjuvant vaccine is superior in terms of inducing cellular immune effectors to a greater extent compared to subunit and split vaccines.

Keywords: vaccines against influenza, subunit immunoadjuvant vaccine, subunit vaccine, split vaccine, cytokine response

\section{INTRODUCTION}

It is known that in order to successfully eliminate the influenza virus, the immune system uses both innate and acquired effectors that underline their importance not only during natural infection, but also during vaccination (1-6). When the influenza virus is introduced into the body, at the first stage, it is recognized and the innate immune response is triggered in order to prevent virus 
penetration and multiplying in the epithelial cells of the respiratory tract. Primary recognition of influenza virus in infected cells is performed by pattern-recognizing receptors (1). Signal cascades, started after receptor activation, stimulate the synthesis of pro-inflammatory cytokines and type I interferons (IFN I) (7-9).

IFN I possess strong antiviral activity due to inhibition of protein synthesis in infected cells and limit viral replication. IFN I induce the expression of ISGs genes, which products are able to inhibit viral replication (10-12). Besides, IFN I stimulate dendritic cells (DCs), which enhance presentation of influenza antigens to $\mathrm{CD}^{+}$and $\mathrm{CD} 8^{+}$T-lymphocytes and contribute to the adaptive immune response triggering $(13,14)$.

While alveolar cells are being infected, alveolar macrophages become activated and phagocyte influenza-infected cells. In addition, activated macrophages begin to produce tumor necrosis factor alpha (TNF- $\alpha$ ), which also contributes to the limitation of viral distribution $(15,16)$. It is known that viremia causes an immune response due to the production of interleukins: IL-1, IL-6, IL-8, TNF- $\alpha$, immunoglobulins $(17,18)$.

Cytokines of the interleukin-1 family play an important role in the development of humoral immune response, IL-1 $\beta$ enhances CD40L-mediated activation of human DC, increasing their ability to control IFN- $\gamma$ secretion in T cells and produce IL-12. L$1 \beta$ directly affects antigen-specific $\mathrm{CD} 8^{+} \mathrm{T}$ cells, enhancing their expansion, survival, migration, and effector function (19). After inoculation of influenza A virus into rat, murine and human macrophage cell lines, elevated concentrations of IFN I, TNF$\alpha$, IL-1, IL-6, and mononuclear cellular chemokine attractants (CCL3/MIP-1 $\alpha$, CCL4/MIP-1 $\beta$, CCL5/RANTES, CXCL10/IP-10) were detected $(20,21)$.

The standard of immunogenicity of any vaccines, including influenza, is the immunity that occurs during natural infection (22).

Perhaps the administration of vaccines against influenza can stimulate cytokine production, which should be limited to a moderate degree. It is known that simultaneous increase of TNF- $\alpha$ level with normalization of IL- $1 \beta$ concentration and excessive (hundreds of times) increase of IL-6 in blood serum in patients with $\mathrm{pH} 1 \mathrm{~N} 1$ influenza virus infection is characterized by aggravation of the condition and the possibility of poor prognosis (23). Changing the profile of Th2-cytokines is important for people with allergopathology, since they have dysregulation of IL-4 secretion: an increase in IgE synthesis in response to IL4 stimulation leads to an increase in IgE-stimulated cytokine synthesis by mast cells capable of producing IL-4, I1-5, and IL-6 (24).

In the last decade, adjuvant-containing vaccines were introduced into practice. Such products either by providing better recognition of antigens, or by enhancing the immune response, provide a good postvaccinal effect. The use of an immunomodulator as an adjuvant leads to an expansion of the spectrum of immune responses involved in the creation of immune protection (25-30). Immunomodulators differ

Abbreviations: PBML, peripheral blood mononuclear leukocytes; DCs, dendritic cells; PO, Polyoxidonium, Azoxymer bromide; T-reg, T-regulatory cells. from each other in origin and mechanism of action. For example, the immunomodulatory effect of adjuvants such as lipopolysaccharide and muramyldipeptide is explained by the involvement of innate immune receptors in this process, followed by stimulation of immune cells (31). However, managing the process of stimulating immune cells using pathogen-associated molecular patterns (PAMP) is very complex. Failure of control can result either in insufficient formation of the immune response, or in the development of an undesirable reaction. In this regard, adjuvants that are not related to PAMP are of greater interest, which include Azoximer bromide, an adjuvant that is widely used in the Russian Federation as part of influenza vaccines. Studies have shown that the use of the Azoximer bromide adjuvant in the vaccine demonstrates a good effect and low reactogenicity, including in women in the second trimester of pregnancy. The use of an anti-influenza vaccine containing Azoximer bromide in pregnant women caused a more pronounced immune effect than when using a subunit adjuvantfree vaccine and did not affect the course of pregnancy and fetal development (26, 27, 32-35).

It can be assumed that the difference in the effectiveness of influenza vaccines may be due to the effect of the adjuvant on the activation of immune effectors, which, as shown above, is closely related, among other things, to the cytokine milieu. Therefore, in order to better understand the mechanism of action of the adjuvant and enhance the ability to control the immune response, the study of the cytokine profile of the adjuvant vaccine is of great interest.

\section{Study Objective}

To investigate the effect of the immunoadjuvant polymer-subunit and adjuvant-free influenza vaccines on the cytokine profile of mononuclear leukocytes.

\section{MATERIALS AND METHODS}

A single-center, open, non-randomized study of cytokine profile in human peripheral blood mononuclear leukocytes exposed to vaccines against influenza virus.

\section{Patient Description}

Twenty-seven subjects, corresponding to the inclusion criteria, participated in the study.

\section{Inclusion Criteria}

Eighteen to forty years old women, healthy or with comorbidities in the period of remission. They have never been vaccinated against the influenza and have not experienced influenza or other acute respiratory infections within the last 6 months. It was taken venous blood samples for incubation with influenza vaccines.

\section{Exclusion Criteria}

History of vaccination against influenza, influenza, or other acute respiratory infections within the last 6 months before the study, administration of other vaccines within 30 days before the study, presence of significant diseases in exacerbation stage (nervous, cardiovascular, respiratory 
(including asthma), gastrointestinal, hepatic, metabolic, and hematological diseases), presence of rheumatic, autoimmune diseases, primary or secondary immunodeficiency, history of immunosuppressive therapy, or treatment with immunostimulants.

\section{Study Vaccines}

Influvac ("Abbott biologicals" B.V., Netherlands)_inactivated subunit influenza vaccine, Vaxigrip ("Sanofi Pasteur," France)— inactivated split-virion influenza vaccine for influenza prevention. These vaccines contain hemagglutinin of the influenza virus type A subtypes A/H1N1 $\aleph$ A/H3N2 (15 $\mu \mathrm{g}$ each) and hemagglutinin of the influenza virus type $\mathrm{B}$ (15 $\mu \mathrm{g})$. Grippol plus (LLC "NPO Petrovax Pharm," Russia) trivalent polymer subunit inactivated influenza vaccine. It contains hemagglutinin of the influenza virus type A subtypes $\mathrm{A} / \mathrm{H} 1 \mathrm{~N} 1 \aleph \mathrm{A} / \mathrm{H} 3 \mathrm{~N} 2$ and hemagglutinin of the influenza virus type B (5 $\mu \mathrm{g}$ each), and immunoadjuvant Azoxymer bromide (Polyoxidonium) $(500 \mu \mathrm{g})$. All the vaccines contained current influenza virus strains for epidemiological seasons 2015-2016 and 2016-2017.

The drug product "Grippol plus" is available only in the composition with an adjuvant. There is no similar subunit vaccine with a similar structure containing $5 \mu \mathrm{g}$ of antigens in one vaccination dose without an adjuvant.

\section{Characteristics of Adjuvant Used in the Vaccine}

In the Russian Federation, the immunomodulator Azoxymer bromide is successfully used in many disorders separately or in combination with vaccination (36-39). Azoximer bromide is a water-soluble synthetic polymer adjuvant class of heterochain polyamines-copolymer of $\mathrm{N}$-oxide 1,4-ethylene piperazine $(\mathrm{N}$ carboxyethyl)-1,4-ethylene piperazine bromide. Pharmaceutical development and preclinical studies of the vaccine adjuvant were conducted for several years in the early 90's of the 20th century. According to literature data, Azoxymer bromide interacts with three lymphocyte subclasses, predominantly binds to monocytes and neutrophils, and to a lesser extent-with lymphocytes, which leads to increased intracellular $\mathrm{H} 2 \mathrm{O} 2$ production. Hydrogen peroxide activates the transcription factor NF-kB, which is involved in the regulation of cytokine synthesis. Increased synthesis of pro-inflammatory cytokines IL- $1 \beta$, IL6 , TNF- $\alpha$ is observed, that direct the immune response to Th1 cell type and do not cause an increase in IgE levels (40). On a number of model compounds, it was shown that the immunogenicity and protective properties of antigens attached to the Azoximer bromide carrier increase 10-fold with an increase in both the antibody and cell-mediated immune response, the synthesis of all classes of protective antibodies (IgM, IgG, $\operatorname{IgA}$ ) is enhanced, but the synthesis of allergic $\operatorname{IgE}$ antibodies is not stimulated. Thus, some synthetic polyions are strong adjuvants and polyclonal activators of B-and T-lymphocytes (41). Grippol ${ }^{\circledR}$ plus is produced according to international GMP and ISO ISO:9001 standards in clean rooms on the filling line with hurdle technology, which allows excluding the mercurycontaining preservative (thiomersal) from the composition of vaccine.

Polymer-subunit influenza vaccine is included in the National immunization schedule of the Russian Federation and has been used for more than 20 years. This vaccine has also been successfully used in a number of other countries: Uzbekistan, Iran, Kyrgyzstan, Belarus.

\section{Laboratory Methods}

Peripheral blood mononuclear leukocytes (PBML), preliminary isolated from whole blood in a Ficoll-Urografin density gradient, were studied. $10^{6}$ cells in $1 \mathrm{~mL}$ of RPMI-1640 with Hepes (PanEco, Russia), containing $0.1 \mathrm{mg} / \mathrm{mL}$ gentamicin sulfate (Sigma), glutamine $(0.32 \mathrm{mg} / \mathrm{mL})$, and $10 \%$ thermo-activated fetal calf serum (PanEco, Russia) were incubated with $10 \mu \mathrm{L}$ of the appropriate vaccine product for $24 \mathrm{~h}$ at $37^{\circ} \mathrm{C}$ in a humidified atmosphere at $5 \% \mathrm{CO}_{2}$.

Doses of the drug product were selected as follows: an adult has an average of $50 \times 10^{9}$ white blood cells in $5 \mathrm{~L}$ of blood, and one vaccination dose of the influenza vaccine is $0.5 \mathrm{ml}$. From this calculation, $10 \mu \mathrm{l}$ of vaccine will be required per $1 \mathrm{ml}$ of cells.

Each patient's cells were incubated separately with each influenza vaccine. The control sample was incubated without the presence of the vaccine.

For the subsequent cytokine analysis using Multiplex-13 test system, the culture supernatants were collected and stored at $-80^{\circ} \mathrm{C}$.

Cytokine (Th1/Th2/Th17/Th9/Th22) level in PBML supernatants was determined after incubation with vaccines against influenza by flow cytometry method (Cytomix FC500, Beckman Coulter, USA) using the Multiplex-13 test system (Bender MedSystems, Austria) according to the method described in the manufacturer's instructions. A 3-fold measurement of each sample was made.

\section{Statistical Analysis}

Groups were compared using Mann-Whitney rank sum tests for independent samples. $P \leq 0.05$ were considered statistically significant (STATISTICA 10 software).

\section{RESULTS}

When exposed to vaccines against influenza (respectively, subunit, immunoadjuvant, and split-), Th-1 cytokine levels were increased compared to the control (PBML supernatant without vaccines): IL-12 level--10.8, 18.7, and 16.5 times higher compared to control (from 6.0 to $65,112.4$, and $99.4 \mathrm{pg} / \mathrm{mL}$, SD $=12,21,7, p<0.001$; Figure 1). At the same time, the activity of the immunoadjuvant vaccine was 1.7 times higher relatively to the subunit vaccine $(p<0.001)$ and 1.1 times higher compared to split vaccine $(p>0.05)$.

IFN- $\gamma$ levels were 15.1, 49.4, and 38.3 times higher compared to the control (from 4.2 to $63.5,207.5$, and $160.9 \mathrm{pg} / \mathrm{mL}$, SD $=9.4,22,20, p<0.001)$. IFN- $\gamma$ level increase was the least pronounced in response to subunit vaccine compared to other vaccines $(p<0.001)$. 

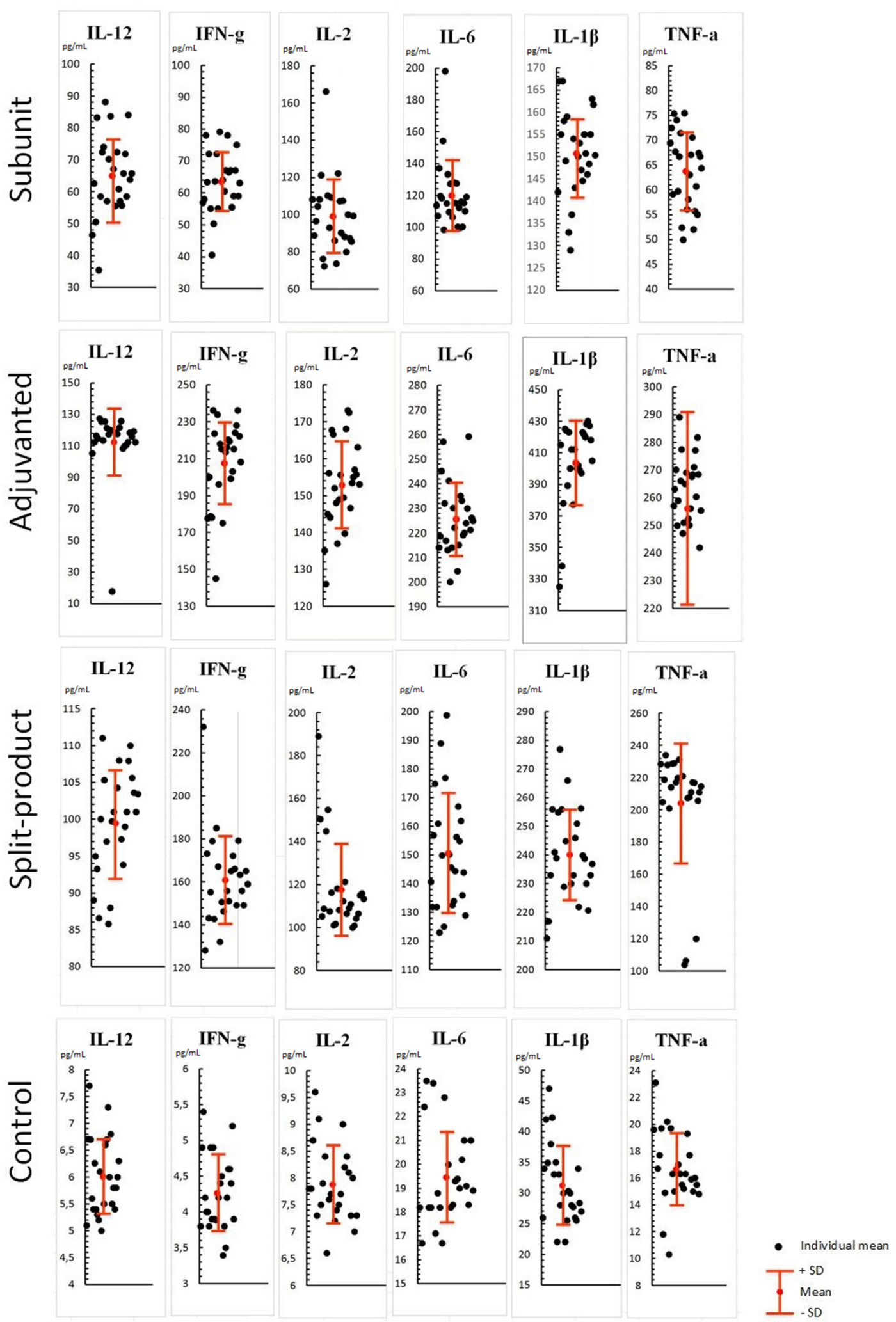

FIGURE 1 | Effect of vaccines against influenza on Th-1 cytokine levels in PBML culture. PBML were isolated from peripheral blood. Cytokine level in PBML supernatants was determined $24 \mathrm{~h}$ after incubation with vaccines against influenza by flow cytometry. All data are shown as individual means, $\mathrm{M}$ (mean values) $\pm \mathrm{SD}$ (standard deviation). The significance of differences between mean values at each time point was tested by Mann-Whitney rank sum tests for independent samples $(P$ $\leq 0.05)$. 
IL-2 levels were12.7, 19.5, and 15 times higher compared to the control (from 7.8 to $99.1,152.8$, and $117.6 \mathrm{pg} / \mathrm{mL}, \mathrm{SD}=20$, $11,21, p<0.001)$. There was no statistically significant difference observed between the subunit and split vaccine $(p>0.05)$, in contrast to the immunoadjuvant vaccine, which activated IL-2 production more actively than the subunit (1.5 times higher, $p$ $<0.001)$ and split vaccines (1.2 times higher, $p<0.005$ ).

Similar pattern was observed in relation to IL-6 levels which were increased by $6.1,11.6$, and 7.7 times compared to the control (from 19.4 to $119.8,225.6$, and $150.7 \mathrm{pg} / \mathrm{mL}, \mathrm{SD}=21,14,20$, $p<0.001)$.

IL-1 $\beta$ levels were $4.8,12.9$, and 7.6 times higher compared to the control (from 31.2 to $150,403.7$, and $240.1 \mathrm{pg} / \mathrm{mL}$, $\mathrm{SD}=9.7,26.9,15.8, p<0.001)$. This cytokine level showed maximum increase among all Th-1 cytokines, especially when immunoadjuvant vaccine was used. The concentrations of IL- $1 \beta$ increased by 2.6 and 1.7 times compared with the subunit and split vaccines $(p<0.001)$.

TNF- $\alpha$ levels were 3.8, 15.4, and 12.2 times higher compared to the control (from 16.6 to 63.7, 256, and $204 \mathrm{pg} / \mathrm{mL}$, SD = $7.7,35,37.4, p<0.001)$. There were no significant differences between immunoadjuvant and split vaccines $(p>0.05)$, while these vaccines caused a statistically significant increase in TNF- $\alpha$ levels compared to subunit vaccine ( 4 and 3.2 times, respectively, $p<0.001)$.

Therefore, all the studied influenza vaccines caused increased levels of all Th-1 cytokines in the PBML culture fluid, which may evidence the cellular immune response activation. At the same time, maximum activity was shown for immunoadjuvant vaccine, lowest activity - for the subunit vaccine, so that, split vaccine was in intermediate position.

When exposed to vaccines against influenza (respectively, subunit, immunoadjuvant, and split-), Th-2 cytokine levels were also increased compared to the control (PBML supernatant without vaccines): IL-10 levels were 13.9, 14.3, and 14.9 times higher compared to the control (from 11 to 152.9, 157.7, and $163.9 \mathrm{pg} / \mathrm{mL}, \mathrm{SD}=18.6,18.3,11.6, p<0.001)$. There were no significant differences between the groups ( $p>0.05$; Figure 2 ).

IL-13 levels were 3.5, 3.7, and 4.2 times higher compared to the control (from 33.2 to $116.3,122.9$, and $140.4 \mathrm{pg} / \mathrm{mL}, \mathrm{SD}=$ 9.8, 8.5, 20.1, $p<0.001)$. There were no significant differences observed between subunit, immunoadjuvant, and split vaccines $(p>0.05)$.

IL-4 levels were $4.5,2.4$, and 2.5 times higher compared to the control (from 25.1 to $114.4,62$, and $62.5 \mathrm{pg} / \mathrm{mL}, \mathrm{SD}=8.1,9.2$, $12.8, p<0.001)$. The activity of the subunit vaccine was 1.8 times higher than of immunoadjuvant and split vaccines $(p<0.001)$.

IL-5 levels were 6.1, 10, and 12.1 times higher compared to the control (from 25.9 to $158.8,258.4$, and $315.3 \mathrm{pg} / \mathrm{mL}, \mathrm{SD}$ $=12.7,16.7,26, p<0.001)$. The activity of the split vaccine was significantly higher compared to the subunit (2 times) and immunoadjuvant vaccines ( 1.2 times), $p<0.001$.

Therefore, all studied vaccines leaded to increased levels of all Th-2 cytokines in leukocyte supernatants, which indicates humoral immunity activation. Regarding IL-4, it can be concluded that the immunoadjuvant and split vaccine had similar potential, consisting in the increase of this cytokine level by 1.8 times, $p<0.001$. The subunit vaccine was the most active in regard to IL-4 stimulation. Split vaccine had more pronounced effect on IL-5 production.

When exposed to vaccines against influenza (respectively, subunit, immunoadjuvant, and split-), IL-17A, IL-9, IL-22 levels increased compared to the control (PBML supernatant without vaccines): IL-17A levels were 3.6, 3.5, and 3.8 times higher compared to the control (from 53.8 to 197, 192.6, and 208.9 $\mathrm{pg} / \mathrm{mL}, \mathrm{SD}=22.8,17.1,32.8, p<0.001$; Figure 3). Difference between experimental groups was not statistically significant $(p>0.05)$.

IL-9 levels were 5.4, 7.3, and 5.7 times higher compared to the control (from 16.2 to $87.9,118.3$, and $93.8 \mathrm{pg} / \mathrm{mL}, \mathrm{SD}=13.8,9$, $14.7, p<0.001)$. The activity of the immunoadjuvant vaccine was 1.3 times higher than of the subunit vaccine and 1.2 times higher than of the split vaccine- $(p<0.001)$.

IL-22 levels were $4.5,10$, and 5.8 times higher compared to the control (from 17.4 to $78.2,179.1$, and $102 \mathrm{pg} / \mathrm{mL}, \mathrm{SD}=6,8.4$, $7.5, p<0.001)$. The activity of the immunoadjuvant vaccine was 2.2 times higher than of the subunit vaccine and 1.7 times higher than of the split vaccine- $(p<0.001)$. Statistical differences between the subunit and split vaccine groups were identified. The activity of the last one was 1.2 times higher $(p<0.05)$.

All vaccines caused increased levels of IL-17A, IL-9, IL22 cytokines in the PBML culture fluid. The immunoadjuvant vaccine had a more pronounced potential for IL-9 and IL-22 activation in comparison with subunit and split vaccines.

\section{DISCUSSION}

The development of modern technologies for the production of influenza vaccines using adjuvants can increase the immunogenicity of drug products. This is achieved both by affecting inductor cells and effectors of the immune response. The mechanism of development of the immune response and formation of immunological memory includes a wide variety of interrelated and interdependent processes. An integral component of these processes is cytokines produced during the immune response and creating a certain microenvironment for cells involved in the formation of immune protection. Thus, by evaluating the production of cytokines by immune cells, we can indirectly judge both the activity of these cells, and better understand the necessary cytokine microenvironment that leads to high immunogenicity. And also thanks to such studies, the role of the adjuvant becomes more clear.

The study showed that the immunoadjuvant vaccine containing Azoximer bromide more actively induced the synthesis of Th1 cytokines (IL-12, INF- $\gamma$, IL-2, IL-6, IL-1 $\beta$, TNF- $\alpha$ ), while the subunit showed minimal effect on their level in comparison with both the immunoadjuvant and split vaccine. These data correlate with our previous studies. POcontaining adjuvanted vaccine showed the strongest capability of inducing the cellular response, among the three vaccines studied, increases in the number of the innate and acquired immunity effectors: NK cells, NKT cells, B lymphocytes, cells with early 

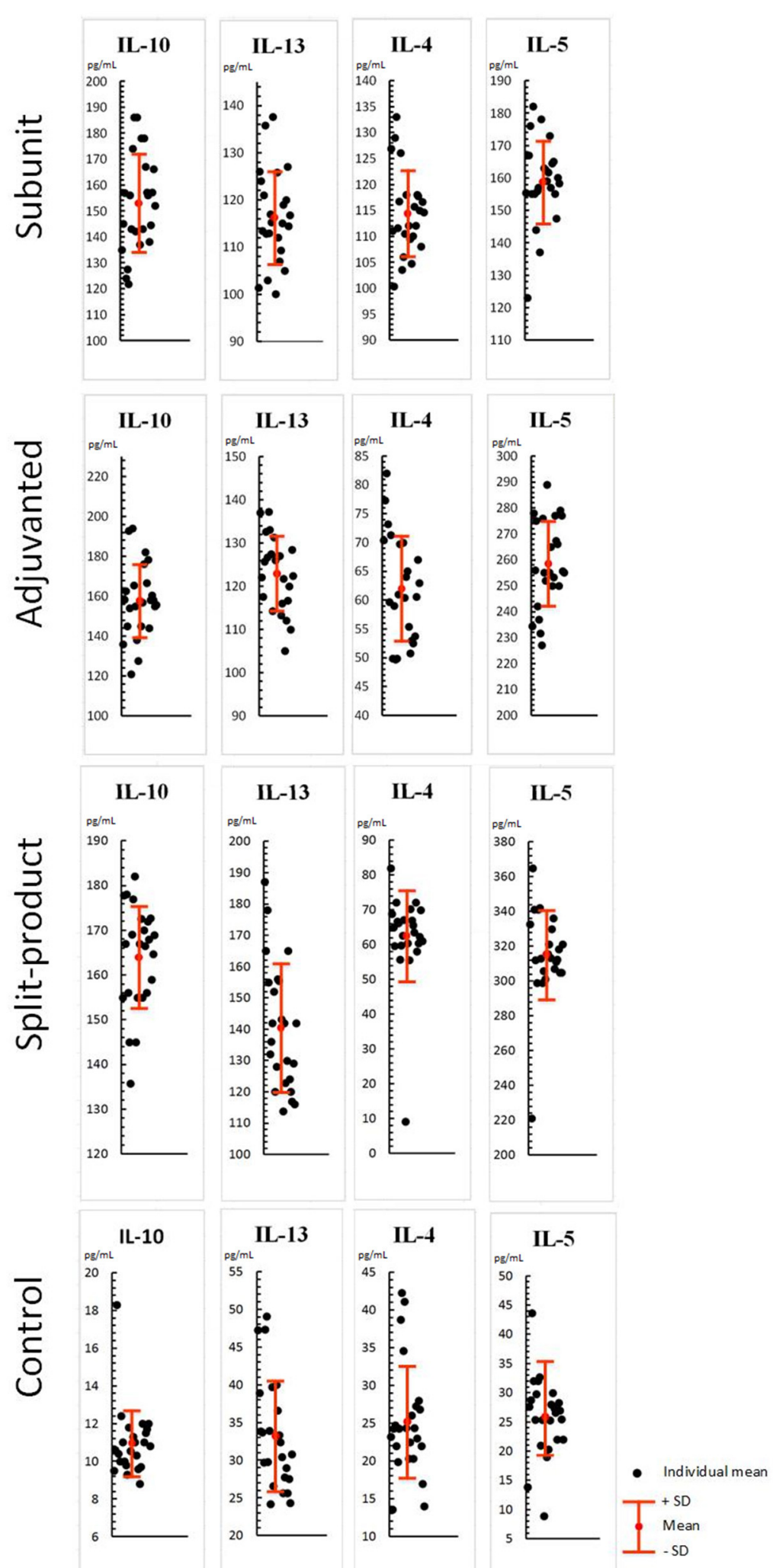

FIGURE 2 | Effect of vaccines against influenza on Th-2 cytokine levels in PBML culture. PBML were isolated from peripheral blood. Cytokine level in PBML supernatants was determined $24 \mathrm{~h}$ after incubation with vaccines against influenza by flow cytometry. All data are shown as individual means, $\mathrm{M}$ (mean values) $\pm \mathrm{SD}$ (standard deviation). The significance of differences between mean values at each time point was tested by Mann-Whitney rank sum tests for independent samples $(P \leq 0.05)$. 

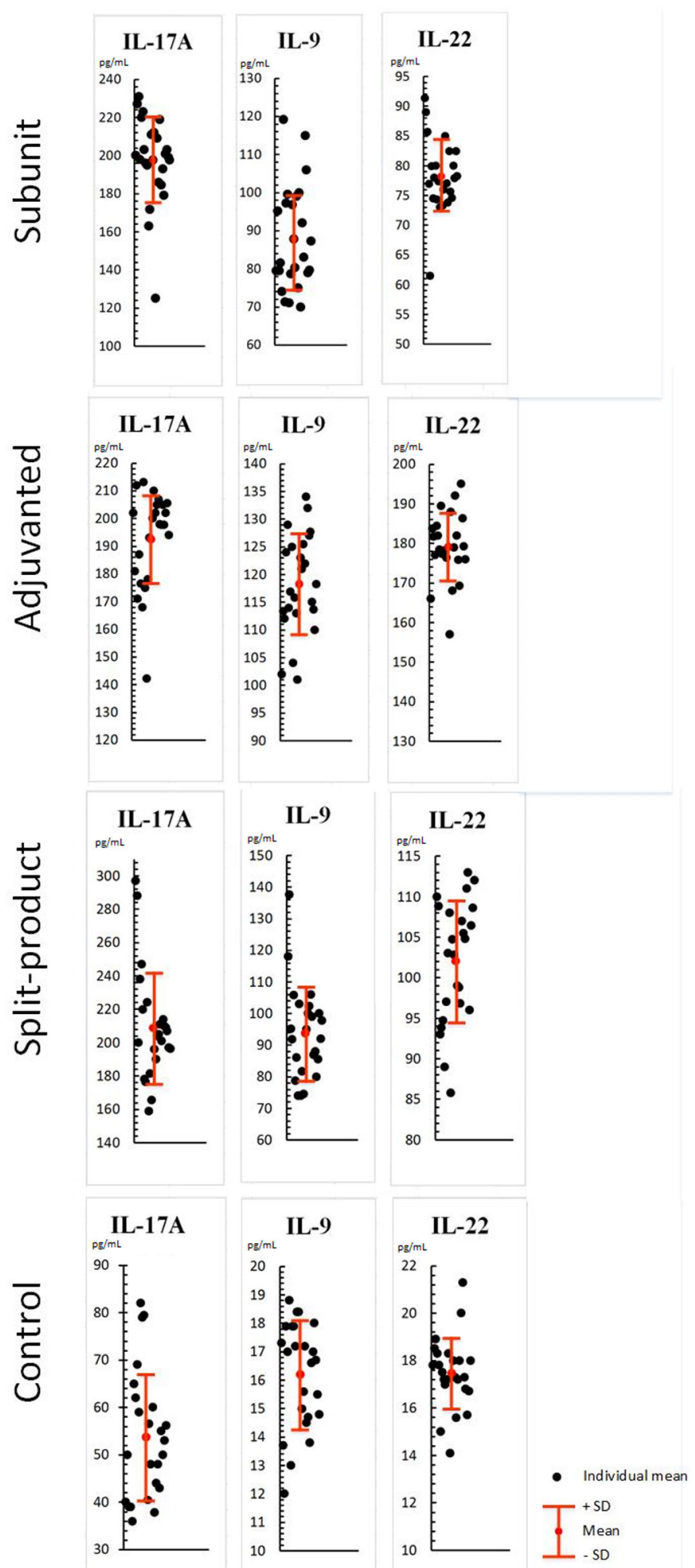

FIGURE 3 | Effect of vaccines against influenza on Th-17/Th-9/Th-22 cytokine levels in PBML culture. PBML were isolated from peripheral blood. Cytokine level in PBML supernatants was determined $24 \mathrm{~h}$ after incubation with vaccines against influenza by flow cytometry. All data are shown as individual means, $\mathrm{M}$ (mean values) $\pm \mathrm{SD}$ (standard deviation). The significance of differences between mean values at each time point was tested by Mann-Whitney rank sum tests for independent samples $(P \leq 0.05)$ 
activation marker, $\mathrm{T}$ lymphocytes with late activation marker, and regulatory $\mathrm{T}$ cells (25).

It should be noted that the results of the cytokine profile were evaluated without taking into account the initial antibody titers. However, when evaluating the parameters of the cellular immune response, the following results were obtained: in individuals with initially low antibody titers (titer 1:20-1:40), all types of vaccines demonstrated effectiveness in activating the cellular component of immune system, while in individuals with medium (1:80$1: 160)$ and high antibody titers $(1: 320$ and $<$ ) to influenza virus strains, the advantage of the adjuvant vaccine was revealed (25).

IL-12, INF- $\gamma$, and IL-2 are better known for their regulatory function, and IL-6, IL- $1 \beta$, and TNF- $\alpha$ are proinflammatory cytokines, the most potent of which is IL-1 $\beta$. On the one hand, this may be alarming, on the other hand, analysis of the functions of IL- $1 \beta$ shows its important participation in the formation of a post-vaccination immune response. In particular, it is known that IL-1 $\beta$ is a powerful activator of dendritic cells. IL-1 $\beta$, participating in increasing CD40L-mediated activation of dendritic cells, increases their ability to control the secretion of IFN- $\gamma$ in T cells (42) and produce IL-12 (43). Thus, it is possible that the activity of Th2 cells in relation to the production of IL-12, INF- $\gamma$ is not mediated by IL- $1 \beta$. In addition, IL- $1 \beta$ directly affects antigen-specific $\mathrm{CD}^{+} \mathrm{T}$ cells, enhancing their expansion, survival, migration, and effector function, including granzyme B expression and IFN- $\gamma$ secretion (44). Thus, IL-1 $\beta$ is equally, and possibly more than, other cytokines, involved in creating an optimal cytokine environment for the formation of a cellular immune response involving $\mathrm{DC}, \mathrm{CD}^{+}$, and $\mathrm{CD} 8^{+}$cells. Concerns about the development of an inflammatory reaction are not justified, since the use of an adjuvant vaccine as part of routine practice for many years has proven its safety. Moreover, analysis of the results of clinical trials involving an adjuvant vaccine demonstrates a comparable reactogenicity profile and number of systemic reactions compared to a non-adjuvant subunit influenza vaccine.

In terms of activity against IL-4 and IL-5, the adjuvant vaccine took an intermediate place. The subunit vaccine had a stronger effect on IL-4 production, while the split vaccine had a stronger effect on IL-5 production. Producers of IL-4 and IL-5 are also known to be Th2 cells.

It is also known that IL-4 can be synthesized not only by activated T-lymphocytes, but also by basophils and mast cells. The spectrum of biological action covers the suppression of the inflammatory response and increased activation of humoral immune response (45). And the significance of these cytokines increases significantly in the $\mathrm{T}$ and $\mathrm{B}$ areas of the lymph node. High levels of IL-4 may play a negative role in patients with allergic pathology, and hyperproduction of IL-4 may provoke an anabasis (46-48).

The absence of IL-4 hyperproduction when using an adjuvant vaccine explains the results of clinical studies in which literature analysis shows that when vaccination against influenza with a subunit vaccine with an Azoximer bromide adjuvant in children with allergic diseases, there was a significant decrease in the content of IgM and total IgE in the blood serum after 1 month and there was a tendency to increase endogenous IFN- $\gamma$ and
IL-12 (49). Therefore, the use of the studied immunoadjuvant vaccine was not accompanied by an increase in sensitization in individuals with allergic pathologies.

These results of the study have shown a more significant effect of the immunoadjuvant vaccine on IL-9 and IL-22 levels in comparison with subunit and split vaccines. The cytokine IL-9 was identified and its main characteristics were described more than three decades ago. Earlier, IL-9 was considered to be Th2-cytokine, as it promotes the development of allergic inflammation and is associated with various Th2-type responses (50). Later studies have shown the multifunctional activity of this cytokine. IL-9 turned out to be a key molecule, that affects Th17 cell differentiation and T-reg functions. IL-9 enhances the suppressor function of Foxp $3^{+} \mathrm{CD} 4{ }^{+} \mathrm{T}$-regs in vitro, and absence of IL-9 signaling reduces the inhibitory activity of T-regs in vivo, which leads to increased number of effector cells. IL-9 is secreted by a recently discovered $\mathrm{CD}^{+} \mathrm{T}$ helper subpopulation-Th9cells that differ from Th1, Th2, and Th17 (51). It should be noted that immunoadjuvant-containing vaccine was the only one that increased T-regs number (25). It can be assumed that a more pronounced stimulation of this cytokine in combination with an increase in the number of T-reg happening under the influence of an immunoadjuvant vaccine, has a regulating effect on the immune response, preventing immune system hyperactivation.

IL-22 exerts functions, similar to IL-17; both cytokines contribute to the control of extracellular bacterial infections (52). The main biological role of IL-22 includes the enhancement of innate immunity, protection from damage, as well as increase regeneration (51).

Thus, increased IL-9 and IL-22 levels may indicate increased cellular regulatory functions in the immune response and activation of the innate mechanisms of the immune system in response to influenza vaccines, in particular, containing immunoadjuvants.

\section{CONCLUSION}

Studied vaccines against influenza were associated with increased levels of Th1/Th2/Th17/Th9/Th22 cytokines in the PBML culture fluid, which indicates both humoral and cellular immunity activation. Immunoadjuvant vaccine is superior in terms of inducing cellular immune effectors to a greater extent compared to subunit and split vaccines.

\section{DATA AVAILABILITY STATEMENT}

The datasets generated for this study are available on request to the corresponding author.

\section{ETHICS STATEMENT}

The studies involving human participants were reviewed and approved by Ethics committee in I.I. Mechnikov Research Institute of Vaccines and Sera, Moscow, Russia. The patients/participants provided their written informed consent to participate in this study. 


\section{AUTHOR'S NOTE}

The vaccines used biosecurity standards, which is confirmed by the marketing authorizations of the drug product for medical use.

\section{REFERENCES}

1. Thomas M, Pierson M, Uprety T, Zhu L, Ran Z, Sreenivasan CC, et al. Comparison of porcine airway and intestinal epithelial cell lines for the susceptibility and expression of pattern recognition receptors upon influenza virus infection. Viruses. (2018) 10:E312. doi: 10.3390/v10060312

2. Tarbayeva DA, Kostinov MP, Zagorodnyaya ED, Iozefson SA, Cherdantsev AP. The obstetric and perinatal outcomes of acute respiratory infectioncomplicated pregnancy in the second trimester of pregnancy. Obstet Gynecol. (2012) 2:67-71.

3. Tarbayeva DA, Kostinov MP, Iozefson SA, Zagorodnyaya ED. Clinical course and outcomes of influenza A (H1N1) 2009 in pregnant women. J Microbiol Epidemiol Immunobiol. (2011). 4:71-6.

4. Kostinov MP, Cherdantsev AP, Semenova SS, Tarbaeva D, Savisko AA, Serova OF, et al. Obstetric and perinatal outcomes among pregnant women after influenza vaccination and after transferred respiratory infection. Gynecol. (2015) 4:43-6.

5. Kostinov MP, Cherdantsev AP, Savis'ko AA, Tarbaeva D, Solov'yova IL. True and false reactions in pregnant women to introduction of influenza vaccine. Questions Gynaecol Obstetrics Perinatol. (2011) 10:44-8.

6. Cherdantsev AP, KuselmanAI, Sinitsyna MN, Shalyagina ME, Kostinov MP, Tarbayeva DA. Study of the clinical safety of vaccination against influenza in pregnant woman. Med Almanac. (2011) 4:120-2.

7. Becher PM, Hinrichs S, Fluschnik N, Hennigs JK, Klingel K, Blankenberg $\mathrm{S}$, et al. Role of Toll-like receptors and interferon regulatory factors in different experimental heart failure models of diverse etiology: IRF7 as novel cardiovascular stress-inducible factor. PLoS One. (2018) 13:e0193844. doi: 10.1371/journal.pone.0193844

8. Lim R, Barker G, Lappas M. TLR2, TLR3 and TLR5 regulation of proinflammatory and pro-labour mediators in human primary myometrial cells. J Reprod Immunol. (2017) 122:28-36. doi: 10.1016/j.jri.2017. 08.004

9. Lund JM, Alexopoulou L, Sato A, Karow M, Adams NC, Gale NW, et al. Recognition of single-stranded RNA viruses by Toll-like receptor 7. Proc Natl Acad Sci U S A. (2004) 101:5598-603. doi: 10.1073/pnas.0400937101

10. Ivashkiv LB, Donlin LT. Regulation of type I interferon responses. Nat Rev Immunol. (2014) 14:36-49. doi: 10.1038/nri3581

11. Li C, Deng Y-Q, Wang S. 25-Hydroxycholesterol protects host against Zika virus infection and its associated microcephaly in a mouse model. Immunity. (2017) 46:446-56. doi: 10.1016/j.immuni.2017.02.012

12. Wang $\mathrm{P}, \mathrm{Xu}$ J, Wang Y, Cao X. An interferon-independent lncRNA promotes viral replication by modulating cellular metabolism. Science. (2017) 358:10515. doi: 10.1126/science.aao0409

13. Iwasaki A, Pillai PS. Innate immunity to influenza virus infection. Nat Rev Immunol. (2014) 14:315-28. doi: 10.1038/nri3665

14. Murphy K, Weaver C. T cell mediated immunity. In: Toledo M, Bochicchio A, Acevedo-Quinones. C. Janeway's Immunobiology. 9th ed. New York, NY: Garland Science (2017):pp. 345-98.

15. Divangahi M, King IL, Pernet E. Alveolar macrophages and type I IFN in airway homeostasis and immunity. Trends Immunol. (2015) 36:30714. doi: 10.1016/j.it.2015.03.005

16. Hussell T, Bell TJ. Alveolar macrophages: plasticity in a tissue-specific context. Nat Rev Immunol. (2014) 14:81-93. doi: 10.1038/nri3600

17. Jan S, Roose K, Saelens X. Influenza and memory T cells: how to awake the force. Vaccines (Basel). (2016) 4:33. doi: 10.3390/vaccines4040033

18. Short KR, Veeris R, Leijten LM, van den Brand JM, Jong VL, Stittelaar K, et al. Proinflammatory cytokine responses in extra-respiratory tissues during severe influenza. J Infect Dis. (2017) 216:829-33. doi: 10.1093/infdis/jix281
AUTHOR CONTRIBUTIONS

NA, EK, and MK: concept and design of the study. EK and AK: collection and processing of material. NA: statistical processing. All authors: contributed to the article and approved the submitted version.

19. Degen WGJ, Schijns VEJC. Host-derived cytokines and chemokines as vaccine adjuvants. In: Schijns VEJC, O'Hagan DT, editors. Immunopotentiators in Modern Vaccines. Academic Press (2017). p. 65-84.

20. Chan RW, Leung CY, Nicholls JM, Peiris JS, Chan MC. Proinflammatory cytokine response and viral replication in mouse bone marrow derived macrophages infected with influenza $\mathrm{H} 1 \mathrm{~N} 1$ and $\mathrm{H} 5 \mathrm{~N} 1$ viruses. PLoS One. (2012) 7:e51057. doi: 10.1371/journal.pone.0051057

21. Zeng H, Belser JA, Goldsmith CS, Gustin KM, Veguilla V, Katz JM, et al. $\mathrm{A}(\mathrm{H} 7 \mathrm{~N} 9)$ virus results in early induction of proinflammatory cytokine responses in both human lung epithelial and endothelial cells and shows increased human adaptation compared with avian H5N1 virus. J Virol. (2015) 89:4655-67. doi: 10.1128/JVI.03095-14

22. Medunitsyn NV, Olefir Yu V, Merkulov VA. Correction of the immune status during vaccination. Med Immunol. (2017) 19:275 doi: 10.15789/1563-0625-2017-3-275-284

23. Ivanov VV, Shipilov MV. Proinflammatory cytokines and their significance in pH1N1 influenza. North Caucasus Med Gaz. (2012) 4:70-2.

24. Moskalev AV, Sboichakov VB, Rudoy AS. General Immunology with the Basics of Clinical Immunology: Training Manual. Moscow: GEOTAR-Media (2015). p. 351.

25. Kostinov MP, Akhmatova NK, Khromova EA, Skhodova SA, Stolpnikova VN, Cherdantsev AP, et al. Chapter 5: The impact of adjuvanted and nonadjuvanted influenza vaccines on the innate and adaptive immunity effectors. In: Saxena Sh K, editor. Influenza - Therapeutics and Challenges. London: IntechOpen (2018). p. 83-109.

26. Zverev VV, KostinovMP, Cherdantsev AP, Kuselman AI, Kiselev OI, Erofeeva MK, et al. Vaccination Against Influenza in Pregnancy. Federal Clinical Guidelines, Vol. 41. Remedium (2015). p. 1-41.

27. Cherdantsev AP, Kostinov MP, Kuselman AI, editors. Vaccine prevention of influenza in pregnant woman. In: Guidelines for Doctors. 2nd ed., enlarged. Moscow: MDV Grup Art Studio "Sozvezdie” (2014) 112 p.

28. Khromova EA, Akhmatova EA, Skhodova SA, Semochkin IA, Khomenkov VG, Akhmatova NK, et al. Effect of influenza vaccines on subpopulations of blood dendritic cells. J Microbiol Epidemiol Immunobiol. (2016) 5:23-8. doi: 10.36233/0372-9311-2016-5-23-28

29. Khromova EA, Semochkin LA, Akhmatova EA, Stolpnikova VN, Skhodova SA, Sorokina EV, et al. Comparative activity of influenza vaccines: effect on lymphocyte subpopulation structure. J Microbiol Epidemiol Immunobiol. (2016) 6:61-5. doi: 10.36233/0372-9311-2016-6-61-65

30. Khromova EA, Skhodova SA, Stolpnikova VN, Kukina OM, Akhmatova NK, Kostinov MP. Activation of Toll-like receptors by influenza vaccines (in vitro). Med Immunol. (2017) 19:71-2. doi: 10.15789/1563-0625-2017-0

31. Avdeeva Z, Alpatova NA, Akolzina SE, Medunitsin NV. Immunoadjuvant effect of cytokines. Pac Med J. (2009) 3:19-22.

32. Cherdantsev AP, Kostinov MP, Kuselman AI, editors. Vaccine prevention of influenza and other infectious diseases in pregnant woman. In: Guidelines for doctors. 3rd ed., Moscow: Enlarged (2018). p.143.

33. Kostinov MP, Cherdantsev AP, Pakhomov DV. Anti-influenza antibody level in mother-infant pairs depending on trimester of vaccination of pregnant women using immunoadjivant vaccine. J Vaccines Vaccin. (2015) 6:5. doi: 10.4172/2157-7560.1000297

34. Kostinov MP, Cherdantsev AP, Shmitko AD, Akhmatova NK, Kostinova AM, Praulova DA, et al. The efficacy of immunoadjuvant-containing influenza vaccines in pregnancy. In: Afrin F, Hemeg $\mathrm{H}$, Ozbak $\mathrm{H}$, editors. Vaccines. Rijeka: InTech (2017). p. 67-93. Avalialble online at: https://elibrary.ru/item. asp?id=36278795

35. Kostinov MP, Cherdantsev AP, Praulova DA, Kostinova AM, Polischuk VB. Analysis of safety for fetus of immunoadjuvant 
influenza vaccines in pregnant women. Pediatriia. (2017) 96:91-96. doi: 10.24110/0031-403X-2017-96-1-91-96

36. Kostinov MP, Ababiy LL, editors. Guidelines for Vaccination and Immunotherapy for ENT - pathology. Moscow: MDV Group (2019). 448 p.

37. Khaitov RM, Ilyna NI, editors. Allergology and Immunology: National Guidance. Moscow: GEOTAR-Media (2014):656 p.

38. Chuchalin AG, Yasnetsova VV, editors. Chapter 19: Federal guidelines for the use of medicines (Formular System, Reference Edition) Issue XVII. In: Vaccines. Moscow: LLC "Vindox” (2016). 1044 p.

39. Kostinov MP, Chuchalin AD, editors. Guidance for Clinical Immunology in Respiratory Medicine. 1st ed. Moscow: LLC ATMO (2016). 128 p.

40. Dyakonova VA, Dambaeva SV, Pinegin BV, Khaitov RM. Study of interaction between the polyoxidonium immunomodulator and the human immune system cells. Int Immunopharmacol. (2004) 4:1615-23. doi: 10.1016/j.intimp.2004.07.015

41. Karaulov AV, Bykov AS, Volkova NV Rewiew of Grippol family vaccine studies and modern adjuvant development. Epidemiol Vaccin Prev. (2019) 18:101-19. doi: 10.31631/2073-3046-2019-18-4-101-119

42. Bullens DM, Kasran A, Thielemans K, Bakkus M, Ceuppens JL. CD40L-induced IL-12 production is further enhanced by the Th2 cytokines IL-4 and IL-13. Scand J Immunol. (2001) 53:455-63 doi: 10.1046/j.1365-3083.2001.00900.x

43. Nikitina TN, Avdeeva ZhI, Alpatova NA. Study of immune adjuvant effect of cytokines in experimental models. Cytokines Inflamm. (2010) 9: 19-24.

44. Ben-Sasson SZ, Wang K, Cohen J, Paul WE. IL-1 $\beta$ strikingly enhances antigendriven CD4 and CD8 T-cell responses. Cold Spring Harb Symp Quant Biol. (2013) 78:117-24. doi: 10.1101/sqb.2013.78.021246

45. Paul WE. History of interleukin-4. Cytokine. (2015) 75:37. doi: 10.1016/j.cyto.2015.01.038

46. Staumont-Sallé D, Abboud G, Brénuchon C, Kanda A, Roumier T, Lavogiez $\mathrm{C}$, et al. Peroxisome proliferator-activated receptor alpha regulates skin inflammation and humoral response in atopic dermatitis. J Allerg Clin Immunol. (2008) 4:962-8. doi: 10.1016/j.jaci.2007.12.1165

47. Simbirtsev AS. Cytokines in the pathogenesis of infectious and noninfectious human diseases. Med Acad J. (2013) 13:18-41. doi: 10.17816/MAJ13 318-41

48. Kozlov V, Borisov A.G, Smirnova SV, Savchenko AD. Practical Aspects of Diagnosis and Treatment of Immune Disorders. Manual for doctors. Novosibirsk: Science (2009). 274 p.

49. Bulgakova VA, Balabolkin II, Sedova MS, Sentsova TB, Lukina OF, Reutova VS, et al. Using vaccine to prevent flu in children with allergy. Med Council. (2010) 9-10:46-50.

50. Hauber HP, Bergeron C, Hamid Q. IL-9 in allergic inflammation. Int Arch Allergy Immunol. (2004) 134:79-87. doi: 10.1159/0000 78384

51. Khaidukov SV. Minor subsets of T-helper cells (Th thymic naive, Th central naive, Th9, Th22 and $\mathrm{CD}^{+}{ }^{+} \mathrm{CD}^{+}$double positive T-cells). Med Immunol. (2013) 15:503-12. doi: 10.15789/1563-0625-2013-6-503-512

52. Wolk K, Sabat R. Interleukin-22: a novel T- and NK-cell derived cytokine that regulates the biology of tissue cells. Cytokine Growth Factor Rev. (2006) 17:367-80. doi: 10.1016/j.cytogfr.2006.09.001

Conflict of Interest: The authors declare that the research was conducted in the absence of any commercial or financial relationships that could be construed as a potential conflict of interest.

Copyright (c) 2020 Kostinov, Akhmatova, Khromova and Kostinova. This is an openaccess article distributed under the terms of the Creative Commons Attribution License (CC BY). The use, distribution or reproduction in other forums is permitted, provided the original author(s) and the copyright owner(s) are credited and that the original publication in this journal is cited, in accordance with accepted academic practice. No use, distribution or reproduction is permitted which does not comply with these terms. 